\title{
Labour matters: The politics of materials and making in architecture
}

\author{
Cathy Smith
}

\author{
Introduction: Thinking and engaging matter
}

In architecture, many recent material-based discourses focus on the way in which digital drawing and fabrication technologies facilitate experimentation with the formal and affective capacities of materials, particularly through the use of 1:1 scale prototyping. Yet, there is often minimal discussion of the ontological and socio-political issues embedded within these practices; nor how these methodologies might challenge or disrupt established assumptions about materials and, in particular, the organisation of labour during the fabrication process. If the architectural discipline is to aspire to an "inclusive architecture" based on a reconsideration of matter and materials (Borden and Meredith 2012: 2), then it is also crucial to consider all aspects of practice - including labour. To unpack these issues in more depth, the paper refers to French philosopher Gilles Deleuze and psychoanalyst Félix Guattari's critique of the philosophical model of form and matter known as "hylomorphism" and the association of this notion with the segregation of intellectual and manual labour in Western society, including architectural practice. They argue that the hylomorphic concept can be associated with a broader sense of hierarchy within Western philosophy: prompting a way of thinking based on "a society divided into governors and governed, and later, intellectuals and manual laborers" (Deleuze and Guattari 2004: 407). Their association of hylomorphism with classical Western philosophy establishes a specific theoretical context for the present paper.

This paper engages with specific philosophical conceptions in order to draw attention to some problematic assumptions about materials and labour that remain largely unexamined in architectural discourse. The focus is on discourses - philosophical and architectural - that explicitly confront the segregations between form and matter, and designing and making, with a specific concentration on the post-millennium milieu. Examples of contemporary material-focused discourses will elucidate the conceptual relation between materials and making in architecture - including texts by Lisa Iwamoto, Katie Lloyd-Thomas and Bernard Cache. In particular, this paper aims to make explicit that the ways in which materials are conceived and deployed in architecture can support or disrupt established conceptual hierarchies - not only with respect to conceptions of form and matter, but also to making, particularly labour.

\section{Contemporary material-focused thinking within the architectural field}

In her text Digital Fabrications: Architectural and Material Techniques, architect and academic Lisa Iwamoto suggests that "digital media and emerging technologies are rapidly expanding what we conceive to be formally, spatially, and materially possible" (2009: 4). Many of the project examples within this text involve experiments and 1:1 scale prototyping using CAD-CAM (computer-aided design / computer-aided manufacture), CNC (computer numerical control) fabrication tools, robotic assembly and other digitally-enhanced production technologies. The projects are similar in positioning a specific material or fabrication technology as the primary generator of architectural form. This focus on form and materials does not necessarily preclude other considerations, such as functional 
1 Jon Goodun and Karin Jaschke's introduction to a 2012 issue of Architectural Design concerned with material resources refers to the "new, materialist mode of practice" in architecture. Other materialfocused texts include: Robert Sheil's 2005 Design Through Making; Kolarevic and Klinger's 2008 Manufacturing Material Effects: Rethinking Designing and Making in Architecture, and; Gail Peter Borden and Michael Meredith's 2012 Matter:Material Processes in Architectural Production Asterios Agkathidis' 2010 edited text Digital Manufacturing in Design and Architecture also explores the relation between digitally enhanced design methodologies, materials and fabrication processes, but there is arguably still a primary conceptual focus on form-making and the "devices which helped to rationalise and systematise the production process of complex geometries" (Agkathidis 2010: 4). The recent 2013 Australian Institute of Architects' annual conference, titled Material, was dedicated to the same theme (Australian Institute of Architects 2013).

2 This discourse includes the discussion of handcraft and manufacture elaborated within art critic John Ruskin's 1849 text The Seven Lamps of Architecture (1907); and William Morris' 1891 lecture 'The Influence of Building Materials upon Architecture' (1996). These discourses do not necessarily directly invoke the philosophical distinctions between form and matter discussed in the present paper, but they do establish a precedent for discussing the notions of labour and making with respect to fabrication and construction in architecture. building programme, building typology, project budget and so forth - a point reinforced by architects Jesse Reiser and Nanako Umemoto in their 2006 text Atlas of Novel Tectonics (2006: 90). In Iwamoto's words, these projects: “capitalize on material methods as a generator for design" (2009: 7). The projects in Digital Fabrications are also invested with concerns that are "the purview of the low arts or crafts" (4). In both "low-tech" and digital production methodologies, the designer may be more directly involved in the making of an artefact or building component than in mainstream professional practices, where the designer operates independently of the fabricator and/or fabrication process.

The focus on materials, fabrication and form within Digital Fabrications typifies a reinvigorated interest in materiality within contemporary architectural discourse $^{1}$ that frequently concentrates on the potential of materials for experiments with "perceptual, spatial and formal effect" (4). The term "material" is often used as synonymous with "building materials" (Lloyd Thomas 2010: 5) and with only minimal interrogation of its philosophical, ontological and epistemological meanings outside of the architectural discipline. For example, Borden and Meredith's comprehensive text Matter is explicitly concerned with a conception of materials as distilled from specifically architectural practices and debates (2012: 2-3). They identify a "socio-ecological shift" in architecture prompted by the Industrial Revolution, and the consequent widening in scope and availability of the architect's "palette of materials" (1). This concern with architectural materials reinforces, rather than challenges, the traditional focus on the usefulness of materials in architectural form-making and ignores "the cultural and political issues that an engagement with the material might yield” (Lloyd Thomas 2007: 7-8).

Historically, the Industrial Revolution prompted significant changes to traditional production methodologies. This, in turn, generated considerable debate about the attendant issues of labour and craft - as for example in John Ruskin's and William Morris' writings. ${ }^{2}$ It is important to note that there is little discussion about how digital production methodologies might challenge or disrupt habitual assumptions about interrelations between design, fabrication processes and the organisation of labour. To some extent, this lack of interest on the form-matterlabour relation may be attributed to the prevalent focus on the capacities of actual or 'real' materials as a primary generator of architecture and architectural thinking, which testifies to the "desire to construct an inclusive architecture through matter" (Borden and Meredith 2012: 2). Yet, any ambition for a materially-inclusive practice becomes potentially problematic if this discourse excludes other conceptual, social and economic concerns that are intrinsically bound to engagements with matter. Architectural theorist Lloyd Thomas argues that unless the conception of materials and their formations in architecture is explicitly addressed, new production methodologies may simply extend and replicate existing hierarchical assumptions - particularly form's conceptual dominance over matter (2007: 7-9). Accordingly, the paper takes as its focus the conceptual relation between materials and labour as it is engaged in specific examples of philosophy and particular contemporary examples of architectural discourse.

\section{The division of labour and architecture}

Any examination of the notion of labour must proceed with some qualification about how the term is deployed. "Labour" appears to be a particularly nebulous term which refers to the productive aspects of any endeavour: put quite simply, labour generally refers to "work". In architectural discourse, labour might simultaneously invoke physical work or labour involving direct contact with materials 
- for example, the work done by builders on a construction site - and intellectual or work or "thinking", such as thinking about the shape and assemblage of buildings away from the construction site. In reality, the segregations between different types of labour may seem artificial: one could easily argue that architectural drawing concurrently involves intellectual and manual work. For the purposes of clarity, the present paper will refer to and differentiate between "intellectual" and "manual” labour, as Deleuze and Guattari do within A Thousand Plateaus (2004: 407).

It is the hierarchical distinction between intellectual and manual labour that appears to be of significant concern to Deleuze and Guattari with respect to their discussion of form and matter in A Thousand Plateaus. For them, labour is associated with the segregation, classification and quantification of any productive human activity: specifically, "labor is the quantitative comparison of activities" (489). If labour can be separated, measured and potentially "stockpiled", a financial and political value can be ascribed to or extracted from it (Bonta \& Protevi 2004: 103). Accordingly, segregation and division is at the core of any notion of labour. In the words of sociologist Richard Sennett: "[t]he division of labour focuses on parts rather than wholes" (2008: 47). Instead of focusing on social or political causality, Deleuze and Guattari turn to the conceptual relation between form and matter as the generator of the division of labour. They are highly critical of the philosophical model of the form-matter relation known as hylomorphism, which distinguishes between the concepts of form and matter. Hylomorphism produces a sense that matter is passive and devoid of any formal or organisational capacities of its own; it requires form to be "imposed" upon it. By segregating the notion of form from matter, and by suggesting that form dominates matter, hylomorphism may invoke and promote a broader sense of hierarchy (Simondon 2007: 10; Deleuze \& Guattari 2004: 407). While the present paper focuses on Deleuze and Guattari's more contemporary problematisation of hylomorphism, it is important to note that the notions associated with hylomorphism have been ingrained in thought since the origins of Western philosophy. For example, Timaeus and Critias outlines Plato's belief that all matter of the world is an approximation (albeit imperfect) of idealised, perfected forms which exist in the realm of the spirits and beyond the everyday material world (Plato 1977). The inextricable relation between form, materials and labour is also discussed by French philosopher Gilbert Simondon, to whom Deleuze and Guattari refer. In his text The Individual and Its Physico-Biological Genesis, Simondon suggests that the hylomorphic model of form and matter underpins the idea of "social hierarchy" (2007: 10) and the hierarchical thinking typical of Western thought. In the words of geographer Mark Bonta and philosopher John Protevi, the form-matter duality is "the viewpoint of a master commanding slave labour” (2004: 97). Drawing from Simondon, Deleuze and Guattari also suggest that the duality established between form and matter is part of a broader world view relating to "the organisation of work and the social field through work" (2004: 407).

The form-matter model elaborated within A Thousand Plateaus is part of a larger discussion about different models and approaches to life, invoked through specific examples drawn from construction and architecture. They identify two fundamentally different approaches to the building of Gothic cathedrals in the Middle Ages, based on different conceptions of the form-matter relation. The first approach, termed State or royal science, is directly associated with a hierarchical conception of form and matter. It also appears to be associated with architects (Deleuze and Guattari 2004: 406-7; Protevi 2001: 131; Bonta and Protevi 2004: 53). Royal or State science involves applying general rules and abstract models and theorems derived from "real-life" experience (Deleuze and Guattari 2004: 412). 
The State approach aims for "a fixed model of form" and involves "templates", maths and other quantifiable measures (402). The second approach, nomad science, involves discovering and responding to particular problems encountered in "real-life" situations and sites $(406-7,412)$. As described by Deleuze and Guattari, nomadic builders or Gothic "journeymen" would travel across the land to cathedral building sites, drawing from experience and intuition rather than following wholly predetermined building plans, representational drawings or engineering calculations (406). Consequently, there was no discernible differentiation between intellectual and manual labour, nor a hierarchical approach to materials and their formations. These nomadic builders or journeyman were organised, but operated independently of the State and its hierarchical and social models; as such, "the division of labour fully existed, but it does not employ the form-matter duality" (407). Thus the organisation of labour was not founded upon the sense of hierarchy associated with the State science model:

The State's response was to take over management of the construction sites, merging all the divisions of labour in the supreme distinction between the intellectual and the manual, the theoretical and the practical, modelled upon the difference between "governors" and "governed". (Deleuze and Guattari 2004: 406)

In practical terms, advancements in drawing techniques in the late Middle Ages enabled skilled draughtsmen to design entire buildings prior to their construction by separate builders. Architectural theorist Edward Robbins suggests that these advancements in drawing were largely responsible for "the social division of labour within architecture" (1994: 16). Thus architecture became a specialised, intellectual pursuit based in studios and distinct from the messy manual work involved in construction. In Deleuze and Guattari's words: "[t]he ground-level plane of the gothic journeyman is opposed to the metric plane of the architect, which is on paper and off site" (2004: 406). Most importantly, Deleuze and Guattari argue that this hierarchical division of intellectual and manual labour stems from a conceptual schema that presumes that materials receive their form from the master-architect. Indeed, it has been suggested by architects Jesse Reiser and Nanako Umemoto that architectural practice is premised on the belief that "matter is formless and geometry regulates it" (2006: 88). Accordingly, intellectual labour (design) is generally associated with architects and architectural studios: manual labour (construction) is associated with building contractors and manufacturing workshops.

\section{The digitisation of labour}

Engaging with materials in a more heterarchic and "inclusive" manner should also prompt a critique of the attendant organisation of labour in building practice. Contemporary discussions about digital fabrication techniques tend to focus on the self-organisational capacities of materials and associated technologies, without explicitly discussing the distribution of labour during the design, fabrication and assembly project phases. Yet digital production technologies have the capacity to introduce material parameters, production costs and techniques into the digital model (Agkathidis 2010: 4). As such, parameters relating to the deployment of labour could be explicitly considered alongside material capacities. Digital drawing and fabrication technologies can improve the connection between drawings and material fabrication by introducing a direct relation between both; as seen in the example of the CNC router machine which fabricates building components in direct reference to a CAD drawing. There are still inevitable, albeit potentially productive, fissures between what is drawn and what is constructed, particularly 
when human fabricators post-assemble robotically-produced components. Iwamoto does not specifically address the issue of the organisation of labour within digital production methodologies, but she does suggest that there is an inevitable schism between digital visualisation and the subsequent "modes of making" (2009: 4) or assembly.

In a 2010 essay, practitioner, theorist and digital-innovator Bernard Cache engages with the socio-political issues of digitisation and assembly more directly. He criticises the discourse on digital production methodologies for its primary focus on form and universal aesthetics - the "formal curvy-broken style" (2010: 55) - at the expense of other social and cultural concerns. Cache associates the limitations of digital production discourses in architecture with a broader tendency to ignore the social and cultural aspects of computers and computerisation (53). For Cache, this is not a failure of digital production technology per se, but a problem of its theorisation and application. He suggests that it is possible to use CAD-CAM in such a way that it could be tailored to address urban issues and social problems by focusing on how architectural components could be deployed or customised to suit "to the specificity of projects, independent of all formal research" (60). While he does not discuss specific examples for the organisation of labour, he does imply that the manufacture and assembly of digitally-fabricated components can be customised for particular projects such that making and assembly might become equally important concerns alongside building shape and form.

The problem of generalising and anticipating material performance is a key aspect of Deleuze and Guattari's critique of the hylomorphic schema (2004: 451). Whether digital or not, architectural "blueprint" drawings and specifications predict probable behavioural tendencies of materials and their combinations. However, on site, there is usually some degree of deviation, however small (Willis 1999: 225; Alexander 1979: 461-462). Even the most basic specifications tend to acknowledge that there are subtle differences and variations in materials otherwise classified as belonging to a single material type or category (Lloyd Thomas 2010: 52). A case in point is the specification and contract documentation used to construct the experimental Stock Orchard Street house in London (2004), by architects Sarah Wigglesworth and Jeremy Till. Due to the unique material combinations used in this house, the documentation specified not only materials, but included diagrams prescribing their on-site fabrication, such as the design and operation of the scaffolding needed to assemble the unconventional sandbag wall insulation (Lloyd Thomas 2010: 176). They explicitly acknowledged that the fabrication processes involved both material performance and on-site labour, and that these determined the final architectural form (Lloyd Thomas 2010: 180). It is important to note that building contractors were involved in the erection and construction of the building on site.

\section{The architect as manual labourer}

The "design-build" methodology encompasses practices which deliberately integrate the activities of designing with those of fabrication because the designer or architect is also the builder or "labourer", and, sometimes, also the building occupant (Willis 1999: 223). This does not rule out the use of digital production methodologies, although discussion tends to focus on examples of vernacular construction, "low-tech" and small-scale technologies and encompasses a range of often poorly theorised practices including "DIY architecture", "self-build" (Willis 1999: 223) and "Live/Build" (Brand 1995: 202). While these practices may not be labelled materialist, the default integration of designing with making focuses 
attention on material capacities. The design-build methodology in architectural education is often associated with specific North American architecture schools, including the Yale Building Project initiated by Charles Moore and Kent Bloomer in 1967; and Samuel Mockabee's Rural Studio based at Auburn University, Alabama (Sokol 2008: 2). Self-build or Live/Build projects associated with professional architects are routinely referred to as "DIY Architecture" whereby the architect also acts as the builder and building occupant (Smith 2012).

The design-build methodology is often positioned as a way of overcoming the anachronism between architects, builders, clients and building users (Willis 1999: 223). As such, materials tend to be engaged as a secondary and pragmatic concern - in terms of their capacity to be used and shaped, for example - rather than being a core conceptual focus. Nevertheless, projects constructed using self-build methodologies tend to evolve incrementally in response to changes encountered on site, and therefore the self-organisational capacities of materials are arguably an important characteristic of this methodology (Brand 1995: 202). North American critic and writer Stewart Brand invokes the metaphor of "tailored clothing" to characterise self-build projects which are "fine-tuned" to suit their occupants over time (1995: 202). Not only are the specific capacities of individual materials embraced, but also their interrelation with other material conditions and systems. Design-build or self-build projects tend to be of a smaller or residential scale, and are less relevant as a production methodology for larger scale building typologies and contemporary manufacturing contexts. Architect Christopher Alexander and his colleagues have argued that it is possible to construct larger projects using a smaller-scale building approach through decentralised governance and "piecemeal growth" (Alexander, Silverstein, Angel, Ishikawa \& Abrams 1975: 67). Projects are seen to be shaped by the coalescence of multiple influences that often vary over time, including material availability, costs, weathering and so forth; an approach that resonates with Deleuze and Guattari's invocations of nomad science and the attendant blurring of intellectual and manual labour. For nomad scientists, any transformation of matter from one state to another is seen to occur through dynamic encounters and interactions with other forces and, as such, it is difficult to think of matter being passive or disassociated from labour, other materials, tools, techniques and processes: "it is matter in movement, in flux, in variation” (Deleuze and Guattari 2004: 451; Smith 2012: 144).

\section{The labours of matter itself}

A key characteristic of the design-build methodology is the way in which manual labour is intentionally integrated into design processes. The designer-maker exhibits a "willingness to learn from his materials" (Willis 1999: 227). While certain construction technologies such as timber framed construction can be easily adjusted by self-builders in reaction to changes in project conditions, advanced materials may possess the enhanced capacity to self-identify building problems or issues and self-adjust over time; capacities that could be embedded in projects of any scale or type. In his discussion of the self-build approach, Brand refers to new "[s]elf-sensing and self-healing" materials and technologies - such as concrete that self-repairs and cleans in reaction to changing environmental conditions (1995: 221). As such, the materials themselves provide the "manual" labour normally associated with maintenance workers, in addition to possessing the "intellectual" capacity to identify and respond to environmental changes (however limited this capacity may be). Thus the low-tech, hands-on building approach involving self-building could be augmented by new materials with "biological or nano-computerised sensitivity" (221). Brand's observations draw attention to the radical 
possibilities of contemporary biomaterials and nanotechnologies to radically alter the division of labour within a project site, even if he specifically refers to building maintenance and upkeep. In Brand's example, the human labour usually required for particular maintenance activities can be replaced by the self-sensing and selfadjusting matter itself.

Another example concerned with the potential of new biomaterials to revolutionise labour and construction practice can be seen in the 2009 TED talk by academic Rachel Armstrong. Armstrong's visionary talk, titled Architecture That Repairs Itself, focuses on the potential deployment of "metabolic materials for the practice of architecture" (Armstrong 2009). Her interest is in material innovation, rather than the organisation of labour per se. However, there is an explicit reconsideration of the need for human manual labour in building practice, as Armstrong observes, particularly, because most buildings are constructed using "Victorian [era] technology" and "teams of workers" (Armstrong 2009). In collaboration with architect and academic Neil Spiller, Armstrong hopes to engineer a "living material" that can grow and repair itself, thus replacing the aforementioned "teams of workers". Their project, although still under development, involves the invention of a protocell-based metabolic material that can repair water-damaged and submerged foundations of timber buildings in Venice. The particular protocell species used is averse to light, and once deposited in the canal, attaches to the timber piles, potentially resulting in limestone accretion and the growth of a supportive "reef" that could prevent further foundational subsidence. Armstrong acknowledges that the protocell has its own self-organisational capacities, and refers to a "conversation" being enacted between the metabolic building materials and the natural environment (Armstrong 2009). To borrow Reiser and Umemoto's words: "matter proves to have its own capacity for self-organisation" (2006: 88). It is important to note that the protocell is still discussed as instrumental to the goals of the building project, rather than as a sentient independent identity in its own right.

A similar proposal was presented at the 2013 AIA conference Material, by Swiss architect and academic Matthias Kohler who discussed the interrelations between architect and robot during CNC production (Kohler 2013). Kohler argued that robots could be deployed to execute tasks that are difficult for humans to achieve, and vice versa. With reference to Deleuze and Guattari's critique of hylomorphism, it could be argued that the protocell material and the robot might be engaged in similar ways to conventional "architectural" materials - as "slave labour" (Bonta and Protevi 2004: 97) for the execution of formal concepts envisaged by the architect. If, as Iwamoto contends, digital practices can produce a "seamless connection between designing and making” (2009: 4), then this logic must arguably extend to all aspects and phases of an architectural project, including the more heterarchic organisation of labour within the construction site - regardless of whether this labour is metabolic, robotic, cybernetic, or human.

\section{Thinking and making: Both "matter"}

One might argue that labour's aesthetic invisibility within the architectural field contributes to its discernible absence within architectural and scholarly discourse. Materials have qualities that are readily transcribed into architecture and its visual representations; the organisation of labour may lack an obvious or equivalent architectural aesthetic, although labour has been ascribed an aesthetic form in art practice. ${ }^{3}$ Moreover, any discussion of labour raises questions about authorship and the socio-political relations between architects, builders and materials. It is worth noting that very few publications refer to the essential contributions of
3 For example, since the late 1970s, the artist Mierle Laderman Ukeles has based her "Maintenance Art" performative and installation art projects on the notion of labour and its distribution. Her Touch Sanitation project of 1978-1980 involved the artist individually greeting sanitation workers. For further details see her 1969 Manifesto for Maintenance Art, 1969! Proposal for an Exhibition “Care”(Laderman Ukeles 1969). 
builders and manual workers to architectural projects, nor have the perceptions of builders been reflected in architectural discourse. On the surface, contemporary digital fabrication technologies appear to challenge the habitual distinction between designing and constructing buildings because of the close alignment between the computerised drawing and digitally-enhanced fabrication technologies. Nevertheless, digitally-fabricated components must still be assembled within the actual project site and this assembly may be executed by a builder or a separate team of contractors acting under the direction of an architect, and in accordance with building blueprints. As highlighted previously, the establishment of closer ties between drawing and fabrication modes does not, in itself, challenge the customary hierarchies that govern approaches to form, materials and the "organisation of work and of the social field through work" (Deleuze and Guttari 2004: 407). To challenge these habitual practices and ingrained thought processes, it is important to confront fundamental assumptions about matter and materials in relation to the division of labour within the architectural discipline; irrespective of whether architectural processes involve analogue and/or digital production methodologies. Alongside the rapid advances in material and digital manufacturing, it is timely for architectural practitioners and theorists alike to reconsider not only the notion of manual labour, but the very labours of matter itself. 


\section{References}

Agkathidis, A. (Ed.). (2010). Digital Manufacturing in Design and Architecture. Amsterdam: BIS Publishers.

Alexander, C., Silverstein, M., Angel, S., Ishikawa, S. \& Abrams, D. (1975). The Oregon Experiment. New York: Oxford University Press.

Alexander, C. (1979). The Timeless Way of Building. New York: Oxford University Press.

Armstrong, R. (2009, October). 'Rachel Armstrong: Architecture That Repairs Itself' [video file]. In Ted Talks. TEDGlobal, 7.32 min. Retrieved from http://www.ted.com/talks/rachel_armstrong_ architecture_that_repairs_itself.htm

Australian Institute of Architects (2013). Material: the 2013 National Architecture Conference (J. de Manicor \& S. Kaji-O’Grady, Eds.). Melbourne: Australian Institute of Architects.

Bonta, M., \& Protevi, J. (2004). Deleuze and Geophilosophy: A Guide and Glossary. Edinburgh: Edinburgh University Press.

Borden, G. P., \& Meredith, M. (Eds.). (2012). Matter: Material Processes in Architectural Production. London: Routledge.

Brand, S. (1995). How Buildings Learn: What Happens After They're Built. New York: Penguin Books Ltd.

Cache, B. (2010). Obama Versus Irresponsibility: Can Moderation Triumph Over Greed?. In AA Files, 60, 2010 (pp. 53-55).

Deleuze, G., \& Guattari, F. (2004). A Thousand Plateaus: Capitalism and Schizophrenia (Brain Massumi, Ed., Trans.). London: Continuum.

Goodbun, J., \& Jaschke, K. (2012). Architecture and Relational Resources. In J. Goodburn (Ed.), Scarcity: Architecture in an Age of Depleting Resources Architectural Design, Volume 82, issue 4, doi/10.1002/ad.v82.4/issuetoc (pp. 28-33)

Iwamoto, L. (2009). Digital Fabrications: Architectural and Material Techniques. New York: Princeton Architectural Press.

Kohler, M. (2013). Untitled Talk. In Material: the 2013 National Architecture Conference (J. de Manicor \& S. Kaji-O'Grady, Eds.). Melbourne: Australian Institute of Architects.

Kolarevic, B., \& Klinger, K. (Eds.). (2008). Manufacturing Material Effects: Rethinking Designing and Making in Architecture. New York: Routledge.

Laderman Ukeles, M. (1969). Manifesto for Maintenance Art, 1969! Proposal for an Exhibition "Care". Retrieved from http://www.fieldmangallery.com/media/pdfs/Ukeles_MANIFESTO.pdf Lloyd Thomas, K. (2007). Introduction: Architecture and Material Practice. In K. Lloyd Thomas (Ed.), Material Matters: Architecture and Material Practice (pp.2-12). London: Routledge.

Lloyd Thomas, K. (2010, May). Building Materials: Conceptualising Materials Via the Architectural Specification (Unpublished Thesis for the Degree of Doctor of Philosophy). Middlesex University, Centre for Research in Modern European Philosophy, Middlesex University, England.

Morris, W. (1996). The Influence of Building Materials upon Architecture. In C. Miele (Ed.), William Morris on Architecture (pp. 157-171). Sheffield: Sheffield Academic Press.

Plato (1977). Timaeus and Critias (D. Lee, Trans.). London: Penguin Classics, Penguin Books Ltd.

Reiser, J., \& Umemoto, N. (2006). Atlas of Novel Tectonics. New York: Princeton

Architectural Press.

Robbins, E. (1994). Why Architects Draw (1994). Cambridge: The MIT Press.

Ruskin, J. (1907). The Seven Lamps of Architecture. London: J. M. Dent \& Co.

Senett, R. (2008). The Craftsman, London: Penguin Books.

Sheil, R. (Ed., 2005). Design Through Making, Chichester: Wiley-Academy.

Simondon, G. (2007). The Individual and Its Physico-Biological Genesis (Taylor Adkins, Trans.). Section 1, Chapter 1. Paris: Presses Universitaires de France: WordPress.com. Retrieved from http://fractalontology.wordpress.com/2007/10/19/translation-simondon-completion-of-sectioni-chapter-1-the-individual-and-its-physico-biological-genesis/

Smith, C. (2012). Productive matters: the DIY architecture Manuals of Ant Farm and Paolo Soleri (Unpublished Thesis for the Degree of Doctor of Philosophy). The University of Sydney, Sydney, Australia.

Sokol, D. (2008). Teaching by Example: Design-build educators talk pedagogy and real politick In Architectural Record (Digital), Features. Retrieved from http://archrecord.construction.com/ features/humanitariandesign/O810roundtable-1.asp

Willis, D. (1999). The Emerald City and Other Essays on the Architectural Imagination. New York: Princeton Architectural Press. 